\title{
Respiratory involvement parameters in hospitalized COVID-19 patients and their association with mortality and length of stay
}

\author{
Eric Lam DO', Sandra Gomez Paz MD², Dominique Goddard-Harte MD¹, Yosif N. Pak DO³, \\ Joshua Fogel $\mathrm{PhD}^{4}$, Sofia Rubinstein $\mathrm{MD}^{2}$
}

\begin{abstract}
E Lam, SG Paz, D Goddard-Harte, YN Pak, J Fogel, S Rubinstein. Respiratory involvement parameters in hospitalized COVID-19 patients and their association with mortality and length of stay. Can J Respir Ther 2022;58:1-8. doi: 10.29390/cjrt-2021-057.

Introduction/Background: Patients with Coronavirus Disease 2019 (COVID-19) present with a spectrum of respiratory symptoms. There are no studies describing respiratory system involvement adjusted for other organ systems, oxygen saturation nadir, hospitalization days until respiratory involvement, proportion of days of respiratory system involvement, and persistent respiratory involvement at discharge in COVID-19 patients. We studied these parameters in COVID-19 patients that received respiratory therapy interventions and their association with mortality and length of stay (LOS).

Methods: A single-center cross-sectional retrospective study of 738 COVID-19 patients with respiratory involvement at a hospital in the New York metropolitan area.

Results: COVID-19 patients with respiratory involvement had increased mortality with oxygen requirement of $\mathrm{FiO}_{2}>55 \%$ (OR:39.02, 95\% CI:1.59-960.51, $P<0.05)$ and mechanical ventilation (OR:236.64, 95\% CI:8.24-6798.93, $P<0.01)$. Respiratory system involvement adjusted for other organ system involvement was associated with increased mortality (OR:1.60, 95\% CI:1.20, 2.14, $P<0.01)$ and LOS $(B=0.02, \mathrm{SE}=0.01, P<0.01)$. Oxygen saturation nadir of 70\%-89\% was significantly associated with increased LOS ( $\mathrm{B}=0.07, \mathrm{SE}=0.03, P<0.05$ ), whereas oxygen saturation nadir of $<70 \%$ was associated with increased mortality (OR:12.95, 95\% CI:2.72-61.61, $P<0.01)$. An increased proportion of days in hospital with respiratory system involvement was associated with decreased mortality (OR:0.004, 95\% CI: $<0.001-0.06, P<0.001)$ and increased LOS $(B=0.90, S E=0.07$, $P<0.001)$. Respiratory involvement on days $4-7$ was associated with decreased mortality (OR:0.02, 95\% CI: $<0.003-0.17, P<0.001)$, and respiratory involvement on day $>1$ was associated with increased LOS. Respiratory involvement persistent at discharge was associated with increased mortality (OR:56.82, 95\%CI: $18.51-174.43, P<0.001$ ).
\end{abstract}

Conclusions: Among all respiratory parameters, high oxygen requirements and low oxygen saturation nadir are the most predictive of COVID-19 prognosis.

Key Words: COVID-19; SARS-CoV-2; mortality; length of stay; respiratory system

\section{INTRODUCTION}

The Coronavirus Disease 2019 (COVID-19) caused by Severe Acute Respiratory Syndrome Coronavirus 2 (SARS-CoV-2) has a presentation spectrum ranging from asymptomatic infection to severe disease $[1,2]$. COVID-19 is a systemic disease affecting multiple organ systems [3], but primarily presents as pneumonia that affects the respiratory system $[1,4]$. Respiratory failure and acute respiratory distress syndrome (ARDS) are the major complications in severe and critical COVID-19 patients, who often require intensive care unit (ICU) care and invasive mechanical ventilation $[2,5]$.

The severity of respiratory involvement in COVID-19 is mainly measured by clinical characteristics such as oxygen saturation, supplemental oxygen requirement, and the need for invasive mechanical ventilation $[2,5,6]$. Low admission oxygen saturation and the requirement of mechanical ventilation during hospitalization are associated with worse prognosis and mortality in COVID-19 patients [1, 2, 5, 6]. To our knowledge, there are no reports investigating COVID-19 respiratory system involvement and its association with mortality after adjusting for other organ systems involvement [3]. During COVID-19 hospitalization, oxygen saturation nadir and on-admission are important parameters for measuring acute respiratory failure. In fact, seeing as acute respiratory failure is the most common in-patient complication in COVID-19 [7], it is surprising to note that no studies that have investigated oxygen saturation nadir during hospitalization and its association with COVID-19 mortality.

The course of respiratory involvement in COVID-19 patients is described as the development of dyspnea on days 4-10 after the initial onset of symptoms which rapidly progresses to ARDS on days 8-14 in severe cases $[4,8,9]$. Although prior studies have reported rapid progression to ARDS after hospitalization in critical COVID-19 patients [10], data on in-hospital disease progression in noncritical COVID-19 patients are lacking. No studies have investigated the number of days of hospitalization until respiratory involvement, proportion of days with respiratory involvement during hospital stay, and persistent respiratory involvement at discharge in COVID-19 patients. Investigation of these parameters is important to assess the prognosis of both critical and noncritical COVID-19 hospitalized patients. We studied these respiratory

\footnotetext{
${ }^{1}$ Department of Medicine, Nassau University Medical Center, East Meadow, NY, USA

${ }^{2}$ Division of Nephrology $\mathcal{E}$ Hypertension, Department of Medicine, Nassau University Medical Center, East Meadow, NY, USA

${ }^{3}$ Department of Medicine, Albany Medical Center, Albany, NY, USA

${ }^{4}$ Department of Business Management, Brooklyn College, Brooklyn, NY, USA

Correspondence: Sofia Rubinstein, Nassau University Medical Center, Division of Nephrology and Hypertension, 2201 Hempstead Turnpike, Box 49, East Meadow, NY 11554, USA, Fax: 516-572-0082, E-mail: srubinst@numc.edu
}

Published online at https://www.cjrt.ca on 13 January 2022 
parameters in COVID-19 patients with respiratory involvement and their association with mortality and LOS.

\section{METHODS}

\section{Settings and participants}

The study was ethically conducted and approved by the local Institutional Review Board on 15 May 2020. Patients signed a waiver for informed consent was because of the retrospective nature of the study. This was a single-center retrospective study of 738 consecutive patients with laboratory-confirmed COVID-19 (positive SARS-CoV-2 real-time PCR from nasopharyngeal swabs) with respiratory involvement in a tertiary-care public hospital in the New York metropolitan area from 1 March 2020 through 15 May 2020. All eligible patients were included in the study to avoid potential bias. Respiratory involvement was defined as any new requirement of supplemental oxygenation from baseline or nadir oxygen saturation $<92 \%$. All patients had completed their hospital course with either discharge from the hospital or physician-called time of death.

\section{Variables}

Demographic variables included age (years), sex (male/female), race/ ethnicity (Caucasian, African American, Hispanic, East Asian, Southeast Asian (e.g., Indian, Pakistani, and Thai), or other), and insurance status (private, uninsured/emergency Medicaid, regular Medicaid, or Medicare). The comorbidities studied were tobacco use status (never, former, current, or unknown), vaping status (never, current, or unknown), obesity (body mass index $>30 \mathrm{~kg} / \mathrm{m}^{2}$ ), and Charlson Comorbidity Index (CCI) [11]. Disease severity was measured using the quick Sequential Organ Failure Assessment (qSOFA) [12], ICU level of care during hospitalization (no/yes), intubation during admission (no/yes), and maximum oxygen requirement during hospitalization (none, low fraction of inspired oxygen $\left(\mathrm{FiO}_{2}\right) \leq 55 \%$, high $\mathrm{FiO}_{2}>55 \%$, or invasive mechanical ventilation). ICU level of care was defined as either the administration of vasopressor, requirement of $\mathrm{FiO}_{2}>55 \%$, or transfer of the patient to one of the ICUs in the medical center at any time during hospitalization. Low $\mathrm{FiO}_{2} \leq 55 \%$ and high $\mathrm{FiO}_{2}>55 \%$ referred to any modality of noninvasive mechanical ventilation: low $\mathrm{FiO}_{2}$ included nasal cannula and simple face mask, whereas high $\mathrm{FiO}_{2}$ included non-rebreather mask, high flow device, and bilevel positive airway pressure ventilation. Treatment management variables included the use or nonuse of vasopressors (e.g., norepinephrine, vasopressin, dobutamine, epinephrine, or midodrine), antibiotics, nonsteroidal anti-inflammatory drugs (NSAIDs), angiotensin-converting enzyme inhibitors or angiotensin receptor blocker, antivirals (remdesivir), antimalarials (hydroxychloroquine and/or chloroquine), steroids, convalescent plasma from donors with prior COVID-19 infection, interleukin-6 inhibitor (IL-6; tocilizumab), and anticoagulant (e.g., heparin, enoxaparin, apixaban, and warfarin).

Eight organ systems were studied: respiratory, cardiovascular, renal, hepatic, hematologic, endocrine, neurological, and musculoskeletal systems. The number of organ systems involved ranged from 1 to 8 . Respiratory system involvement was defined as any new requirement of supplemental oxygenation from baseline or nadir oxygen saturation $<92 \%$ during hospitalization. Cardiovascular involvement was any new troponin elevation $>0.04 \mathrm{ng} / \mathrm{mL}$, any new heart failure, acute or chronic heart failure, new or uncontrolled atrial fibrillation, supraventricular tachycardia, new atrioventricular block, new ventricular tachycardia, or any new inotrope or vasopressor use. Renal involvement was defined as either an increase in serum creatinine level $>0.3 \mathrm{mg} / \mathrm{dL}$ or 1.5 time increase from baseline, defined as the AKIN criteria [13]. Liver involvement was defined as elevated serum alanine aminotransferase more than 1.5 times the normal limit (>60 IU/L) or abnormal total serum bilirubin $>1.1 \mathrm{mg} / \mathrm{dL}$. Hematologic involvement was defined as a new abnormal count of any one of the four cell lines from the patient's baseline: white blood cell count $<4 \times 10^{9} / \mathrm{L}$ or $>11 \times 10^{9} / \mathrm{L}$, absolute neutrophil count $<1.8 \times 10^{9} / \mathrm{L}$ or $>7 \times 10^{9} / \mathrm{L}$, hemoglobin count $<9.2 \mathrm{~g} / \mathrm{dL}$, or platelet count $<110 \times 10^{9} / \mathrm{L}$. Endocrine involvement was defined as any blood glucose level $<60 \mathrm{mg} / \mathrm{dL}$ or $>140 \mathrm{mg} / \mathrm{dL}$ or any new or higher insulin administration requirement from the baseline. Neurological involvement was defined as any decrease in the Glasgow Coma Scale [14] or change in mental status from baseline, any new onset of seizure, or any new transient ischemic attack or new cerebrovascular accident. Musculoskeletal involvement was defined as creatine kinase values $>1000$ units/L.

Further respiratory status characteristics were studied. Oxygen saturation on admission and nadir oxygen saturation during hospitalization were classified into one of three groups $\left(\mathrm{SpO}_{2} 90 \%-100 \%, 70 \%-89 \%\right.$, or $<70 \%$ ). Respiratory proportion days involved was the proportion of hospital days with respiratory involvement (range 0-1) and was calculated using the number of days with respiratory involvement divided by total hospitalization days. Days to respiratory involvement (day 1, day 2, day 3, day 4-7, or $>7$ days) was the first hospital day with respiratory involvement, where admission day was hospital day 1 . Persistent respiratory involvement at discharge was defined as any respiratory involvement (no/yes) at discharge or death.

The outcome variables were mortality (no/yes) and LOS (days).

\section{Statistical analysis}

Descriptive statistics consisted of mean and standard deviation for the continuous variables and frequency and percentage for the categorical variables. Two models were used to analyze the outcome variables of mortality and LOS. Univariate analyses were used for Model 1 that considered demographic, comorbidity, disease severity, and treatment management variables. A multivariate analysis was used for Model 2 that included all the significant variables from the univariate analyses in Model 1 and added respiratory variables. Mortality was analyzed using logistic regression. LOS was analyzed using linear regression. Logarithmic transformations were performed for the skewed variables. All $P$ values were two-sided. Data analyses were conducted using IBM SPSS Statistics version 26 (IBM SPSS Statistics for Windows. Version 26. Armonk, NY: IBM Corporation; 2019).

\section{RESULTS}

The sample characteristics of the 738 COVID-19 patients with respiratory involvement are shown in Table 1 . The mean age was above 60 years, more than one-third were female, and almost two-thirds were those either African American or Hispanic. Slightly more than one-fifth of the patients had private insurance, more than half never smoked or vaped, and more than one-third were obese. The mean CCI was almost 3, while mean qSOFA on admission was 1.5. More than half the patients required ICU level of care during hospitalization. On admission, only a small percentage of patients required intubation and mechanical ventilation, and a quarter were intubated during the hospital course. Almost all patients received antibiotic treatment and one-third received steroids. There was a mean of four organ systems involved. More than two-thirds had oxygen saturation of $90 \%-100 \%$ on admission, whereas more than half had an oxygen saturation nadir of 70\%-89\% during hospitalization. The respiratory proportion days involved was 0.7 (average of $70 \%$ total hospitalization days with respiratory involvement). In our cohort population, three-quarters had respiratory involvement on the admission day (day 1), and more than half had respiratory involvement at discharge (either alive or dead). Mortality occurred in one-third of the patient sample and the mean LOS was 10.6 days.

The results of the logistic regression analyses for mortality are shown in Table 2 and Figure 1. In the univariate analyses shown in Model 1, increased age, insurance of regular medicaid and medicare, unknown tobacco use, unknown vaping use, increased CCI, increased qSOFA, ICU care level, intubation at admission, oxygen requirement during hospitalization with high $\mathrm{FiO}_{2}$ and ventilation, vasopressor, antiviral, steroid, interleukin inhibitor, and increased number of organs involved were each significantly associated with increased odds of mortality. Hispanic race/ethnicity and current tobacco use were each significantly associated with decreased odds for mortality. In the multivariate analysis shown in Model 2, increased age, oxygen requirement during hospitalization with high $\mathrm{FiO}_{2}$ and ventilation, vasopressor, increased number of organs involved, oxygen saturation nadir $<70 \%$, and persistent 
TABLE 1

Sample characteristics of 738 COVID-19 patients

\begin{tabular}{|c|c|}
\hline Variables & $\begin{array}{c}M(\mathrm{SD}) \text { or } \\
\text { Frequency (Percent) }\end{array}$ \\
\hline \multicolumn{2}{|l|}{ Demographics } \\
\hline Age, years (mean) & $60.5(16.28)$ \\
\hline Sex (female) & $286(38.8)$ \\
\hline \multicolumn{2}{|l|}{ Race/ethnicity } \\
\hline Caucasian & $192(26.0)$ \\
\hline African-American & $180(24.4)$ \\
\hline Hispanic & $312(42.3)$ \\
\hline East Asian & $24(3.3)$ \\
\hline Southeast Asian & $15(2.0)$ \\
\hline Other & $15(2.0)$ \\
\hline \multicolumn{2}{|l|}{ Insurance } \\
\hline Private & $160(21.7)$ \\
\hline Uninsured/Emergency Medicaid & $161(21.8)$ \\
\hline Regular Medicaid & $269(36.4)$ \\
\hline Medicare & $148(20.1)$ \\
\hline \multicolumn{2}{|l|}{ Comorbidities } \\
\hline \multicolumn{2}{|l|}{ Tobacco use } \\
\hline Never & $470(63.7)$ \\
\hline Former & $70(9.5)$ \\
\hline Current & $23(3.1)$ \\
\hline Unknown & $175(23.7)$ \\
\hline \multicolumn{2}{|l|}{ Vaping } \\
\hline Never & $444(60.2)$ \\
\hline Current & $0(0.0)$ \\
\hline Unknown & $294(39.8)$ \\
\hline Obese (yes) & $273(37.0)$ \\
\hline $\mathrm{CCl}$ (mean) & $2.9(2.42)$ \\
\hline \multicolumn{2}{|l|}{ Disease severity } \\
\hline qSOFA (mean) & $1.5(0.63)$ \\
\hline ICU (yes) & $383(51.9)$ \\
\hline Intubation admission (yes) & $44(6.0)$ \\
\hline \multicolumn{2}{|l|}{ Oxygen requirement hospitalization } \\
\hline None & $83(11.2)$ \\
\hline Low $\mathrm{FiO}_{2}(\leq 55 \%)$ & $274(37.1)$ \\
\hline High $\mathrm{FiO}_{2}(>55 \%)$ & $194(26.3)$ \\
\hline Invasive mechanical ventilation & $187(25.3)$ \\
\hline \multicolumn{2}{|l|}{ Treatment management } \\
\hline Vasopressor (yes) & $123(16.7)$ \\
\hline Antibiotic (yes) & $706(95.7)$ \\
\hline NSAID (yes) & $164(22.2)$ \\
\hline ACEi/ARBS (yes) & $85(11.5)$ \\
\hline Antiviral (yes) & $16(2.2)$ \\
\hline Antimalarial (yes) & $620(84.0)$ \\
\hline Steroid (yes) & $245(33.2)$ \\
\hline Convalescent plasma (yes) & $53(7.2)$ \\
\hline Interleukin inhibitor (yes) & $84(11.4)$ \\
\hline Anticoagulant (yes) & $149(20.2)$ \\
\hline \multicolumn{2}{|l|}{ Organ involvement } \\
\hline Respiratory plus other organ systems (mean) & $4.0(1.84)$ \\
\hline \multicolumn{2}{|l|}{ Respiratory involvement } \\
\hline \multicolumn{2}{|l|}{ Oxygen saturation admission } \\
\hline $90-100$ & $502(68.0)$ \\
\hline 70-89 & $212(28.7)$ \\
\hline$<70$ & $24(3.3)$ \\
\hline \multicolumn{2}{|l|}{ Oxygen saturation nadir } \\
\hline $90-100$ & $284(38.5)$ \\
\hline $70-89$ & $376(50.9)$ \\
\hline$<70$ & $78(10.6)$ \\
\hline Respiratory proportion days involved (mean) & $0.7(0.20)$ \\
\hline \multicolumn{2}{|l|}{ Days to respiratory involvement } \\
\hline 1 & $555(75.2)$ \\
\hline 2 & $87(11.8)$ \\
\hline 3 & $34(4.6)$ \\
\hline $4-7$ & $44(6.0)$ \\
\hline$>7$ & $18(2.4)$ \\
\hline
\end{tabular}

TABLE 1 (Continued)

Sample characteristics of 738 COVID-19 patients

\begin{tabular}{lc}
\hline Variables & $\begin{array}{c}\text { M (SD) or } \\
\text { Frequency (Percent) }\end{array}$ \\
\hline Respiratory persistent involvement at discharge (yes) & $400(54.2)$ \\
Outcomes & \\
Mortality (yes) & $249(33.7)$ \\
Length of stay (days) (mean) & $10.6(11.07)$ \\
\hline
\end{tabular}

Note: $M=$ mean, $S D=$ standard deviation, $C C l=$ Charlson Comorbidity Index, qSOFA = quick sepsis related organ failure assessment, ICU = intensive care unit, $\mathrm{FiO}_{2}=$ fraction of inspired oxygen, $\mathrm{NSAID}=$ nonsteroidal anti-inflammatory drug, ACEi = angiotensin-converting-enzyme inhibitors, $A R B=$ angiotensin II receptor blockers. Respiratory plus other organ systems is the number of organ systems involved. Oxygen saturation admission, oxygen saturation nadir, and days to respiratory involvement proportion days were skewed and still skewed even after logarithmic transformation; categorical variables were used instead of continuous variables.

respiratory involvement at discharge were significantly associated with increased odds for mortality. Current tobacco use, increased respiratory proportion days involved, and 4-7 days to respiratory involvement were significantly associated with decreased odds for mortality.

The linear regression analyses for LOS are shown in Table 3. In the univariate analyses shown in Model 1, ICU care level, oxygen requirement during hospitalization with low $\mathrm{FiO}_{2}$, high $\mathrm{FiO}_{2}$ and ventilation, vasopressor, antibiotic, NSAID, antiviral, antimalarial, steroid, convalescent plasma, interleukin inhibitor, anticoagulant, and increased number of organs involved were each significantly associated with increased LOS. Female sex and East Asian race/ethnicity was significantly associated with decreased LOS. In the multivariate analysis shown in Model 2, ICU care level, antibiotic, NSAID, steroid, convalescent plasma, interleukin inhibitor, anticoagulant, increased number of organs involved, oxygen saturation nadir 70\%-89\%, increased respiratory proportion days involved, and all categories of days to respiratory involvement were each significantly associated with increased LOS. Persistent respiratory involvement at discharge was significantly associated with decreased LOS.

\section{DISCUSSION}

We found that increased age, $\mathrm{FiO}_{2}>55 \%$, mechanical ventilation, vasopressor use, increased number of organ systems involved, oxygen saturation nadir of $<70 \%$, and persistent respiratory involvement at discharge were each associated with increased odds for mortality. Current tobacco smoking, increased respiratory involvement proportion days, increased respiratory involvement proportion days, and respiratory involvement starting on days 4-7 were associated with decreased odds for mortality. Sex, race/ethnicity, and insurance status, after multivariate adjustment showed no association with mortality. ICU care level, use of antibiotics, NSAIDs, steroids, convalescent plasma, IL6 inhibitors, and anticoagulants were associated with increased LOS. An increased number of organ systems involved, oxygen saturation nadir of 70\%-89\% during hospital stay, and increased respiratory involvement proportion days were each associated with increased LOS. Respiratory involvement starting on day 2 , day 3, days 4-7, and days $>7$ were each associated with increased LOS as compared with respiratory involvement on day of admission. Persistent respiratory involvement at discharge was associated with decreased LOS. $\mathrm{FiO}_{2}>55 \%$, mechanical ventilation, and oxygen saturation nadir of $<70 \%$ were each not significantly associated with LOS.

We found that respiratory involvement adjusted for all other organ system involvement was significantly associated with increased odds of mortality and LOS. COVID-19 patients with significant respiratory involvement often present with multiple organ systems involvement [1, $3,4]$. Respiratory parameters such as low admission oxygen saturation, ARDS, and mechanical ventilation are associated with increased 
TABLE 2

Logistic regression analyses for mortality

\begin{tabular}{|c|c|c|}
\hline Variables & Model 1 Univariate OR (95\% Cl) & Model 2 Multivariate OR $(95 \% \mathrm{CI})$ \\
\hline \multicolumn{3}{|l|}{ Demographics } \\
\hline Age (years) & $1.05(1.04,1.07)^{\star * *}$ & $1.07(1.03,1.11)^{\star *}$ \\
\hline Sex (female) & $0.99(0.72,1.35)$ & - \\
\hline \multicolumn{3}{|l|}{ Race/ethnicity } \\
\hline Caucasian & 1.00 & 1.00 \\
\hline African American & $0.67(0.44,1.02)$ & $0.82(0.32,2.13)$ \\
\hline Hispanic & $0.47(0.32,0.69)^{* * *}$ & $0.79(0.30,2.08)$ \\
\hline East Asian & $1.59(0.68,3.72)$ & $0.22(0.04,1.36)$ \\
\hline Southeast Asian & $0.67(0.22,2.04)$ & $0.17(0.02,1.63)$ \\
\hline Other & $1.53(0.53,4.40)$ & $2.32(0.18,29.73)$ \\
\hline \multicolumn{3}{|l|}{ Insurance } \\
\hline Private & 1.00 & 1.00 \\
\hline Uninsured/Emergency Medicaid & $0.99(0.59,1.66)$ & $1.17(0.36,3.76)$ \\
\hline Regular Medicaid & $1.78(1.15,2.77)^{*}$ & $1.87(0.67,5.22)$ \\
\hline Medicare & $3.48(2.14,5.66)^{\star \star *}$ & $2.23(0.65,7.71)$ \\
\hline \multicolumn{3}{|l|}{ Comorbidities } \\
\hline \multicolumn{3}{|l|}{ Tobacco } \\
\hline Never & 1.00 & 1.00 \\
\hline Former & $1.47(0.87,2.48)$ & $0.51(0.15,1.80)$ \\
\hline Current & $0.11(0.02,0.85)^{*}$ & $0.01(0.001,0.21)^{* *}$ \\
\hline Unknown & $2.45(1.72,3.51)^{* * *}$ & $1.20(0.49,2.95)$ \\
\hline \multicolumn{3}{|l|}{ Vaping } \\
\hline Never & 1.00 & 1.00 \\
\hline Current & - & - \\
\hline Unknown & $1.10(1.10,1.50)^{\star *}$ & $1.15(0.77,1.72)$ \\
\hline Obese (yes) & $0.92(0.67,1.27)$ & - \\
\hline $\mathrm{CCl}$ & $1.35(1.26,1.44)^{\star * *}$ & $1.07(0.87,1.33)$ \\
\hline \multicolumn{3}{|l|}{ Disease severity } \\
\hline qSOFA & $1.73(1.35,2.22)^{* *}$ & $1.04(0.58,1.88)$ \\
\hline ICU (yes) & $22.03(13.67,35.49)^{\star * *}$ & $0.86(0.11,7.00)$ \\
\hline Intubation admission (yes) & $12.02(5.27,27.39)^{\star \star *}$ & $0.24(0.05,1.09)$ \\
\hline \multicolumn{3}{|l|}{ Oxygen requirement hospitalization } \\
\hline None & 1.00 & 1.00 \\
\hline Low $\mathrm{FiO}_{2}(\leq 55 \%)$ & $5.42(0.71,41.38)$ & $4.61(0.38,56.24)$ \\
\hline High $\mathrm{FiO}_{2}(>55 \%)$ & $49.47(6.74,363.05)^{* * *}$ & $39.02(1.59,960.51)^{*}$ \\
\hline Invasive mechanical ventilation & $446.76(59.79,3338.44)^{* * *}$ & $236.64(8.24,6,798.93)^{\star *}$ \\
\hline \multicolumn{3}{|l|}{ Treatment management } \\
\hline Vasopressor (yes) & $20.58(11.93,35.50)^{\star * \star}$ & $4.14(1.34,12.75)^{\star}$ \\
\hline Antibiotic (yes) & $1.86(0.79,4.37)$ & - \\
\hline NSAID (yes) & $1.35(0.94,1.93)$ & - \\
\hline ACEi/ARBS (yes) & $0.70(0.42,1.16)$ & - \\
\hline Antiviral (yes) & $4.47(1.54,13.02)^{\star *}$ & $1.87(0.14,25.05)$ \\
\hline Antimalarial (yes) & $0.83(0.55,1.25)$ & - \\
\hline Steroid (yes) & $1.87(1.36,2.57)^{\star * *}$ & $0.92(0.39,2.15)$ \\
\hline Convalescent plasma (yes) & $1.56(0.88,2.74)$ & - \\
\hline Interleukin inhibitor (yes) & $1.83(1.16,2.90)^{*}$ & $0.51(0.18,1.45)$ \\
\hline Anticoagulant (yes) & $1.19(0.82,1.73)$ & - \\
\hline \multicolumn{3}{|l|}{ Organ involvement } \\
\hline Respiratory plus other organ systems & $2.70(2.35,3.12)^{\star * *}$ & $1.60(1.20,2.14)^{\star *}$ \\
\hline \multicolumn{3}{|l|}{ Respiratory involvement } \\
\hline Oxygen saturation admission & - & \\
\hline $90-100$ & & 1.00 \\
\hline $70-89$ & & $0.92(0.39,2.14)$ \\
\hline$<70$ & & $0.37(0.05,2.66)$ \\
\hline Oxygen saturation nadir & - & \\
\hline $90-100$ & & 1.00 \\
\hline $70-89$ & & $1.56(0.56,4.37)$ \\
\hline$<70$ & & $12.95(2.72,61.61)^{\star \star}$ \\
\hline Respiratory proportion days involved & - & $0.004(<0.001,0.06)^{\star * *}$ \\
\hline Days to respiratory involvement & - & \\
\hline 1 & & 1.00 \\
\hline 2 & & $0.66(0.17,2.47)$ \\
\hline 3 & & $0.25(0.04,1.49)$ \\
\hline $4-7$ & & $0.02(0.003,0.17)^{\star \star *}$ \\
\hline$>7$ & & $0.34(0.03,4.08)$ \\
\hline Respiratory persistent involvement at discharge (yes) & - & $56.82(18.51,174.43)^{\star \star \star}$ \\
\hline
\end{tabular}

Note: $\mathrm{OR}=$ odds ratio, $\mathrm{Cl}=$ confidence interval, $\mathrm{CCl}=$ Charlson Comorbidity Index, $q S O F A=$ quick sepsis related organ failure assessment, ICU = intensive care unit, $\mathrm{FiO}_{2}=$ fraction of inspired oxygen, NSAID = nonsteroidal anti-inflammatory drug, $A C E i=$ angiotensin-converting-enzyme inhibitors, $A R B=$ angiotensin II receptor blockers, ${ }^{*} P<0.05,{ }^{* *} P<0.01,{ }^{* * *} P<0.001$, Model 2 Nagelkerke $R^{2}=0.85$. Respiratory plus other organ systems is the number of organ systems involved. 


\section{FIGURE 1}

Association of respiratory parameters with in-hospital mortality. Respiratory parameters include oxygen requirement in hospital, oxygen saturation $\left(\mathrm{SpO}_{2}\right)$ nadir in hospital, days to respiratory (resp.) involvement, increased respiratory involvement days, and persistent respiratory involvement at discharge (d.c.). Odd ratios with error bars representing $95 \%$ confidence interval are expressed in logarithmic scale. All variables were adjusted to number of organ system involvement, age, sex, race/ethnicity, insurance status, comorbidities including smoking and vaping histories, obesity, Charlson Comorbidity Index, disease severity including quick sepsis related organ failure assessment, intensive care unit admission, intubation on admission, treatment management, and oxygen saturation on admission. Superscripts: the $P$-value levels are expressed in asterisks for ${ }^{*} P<0.05,{ }^{* *} P<0.01$, and ${ }^{* *} P<0.001$. Abbreviations: resp. $=$ respiratory; d.c. $=$ discharge.

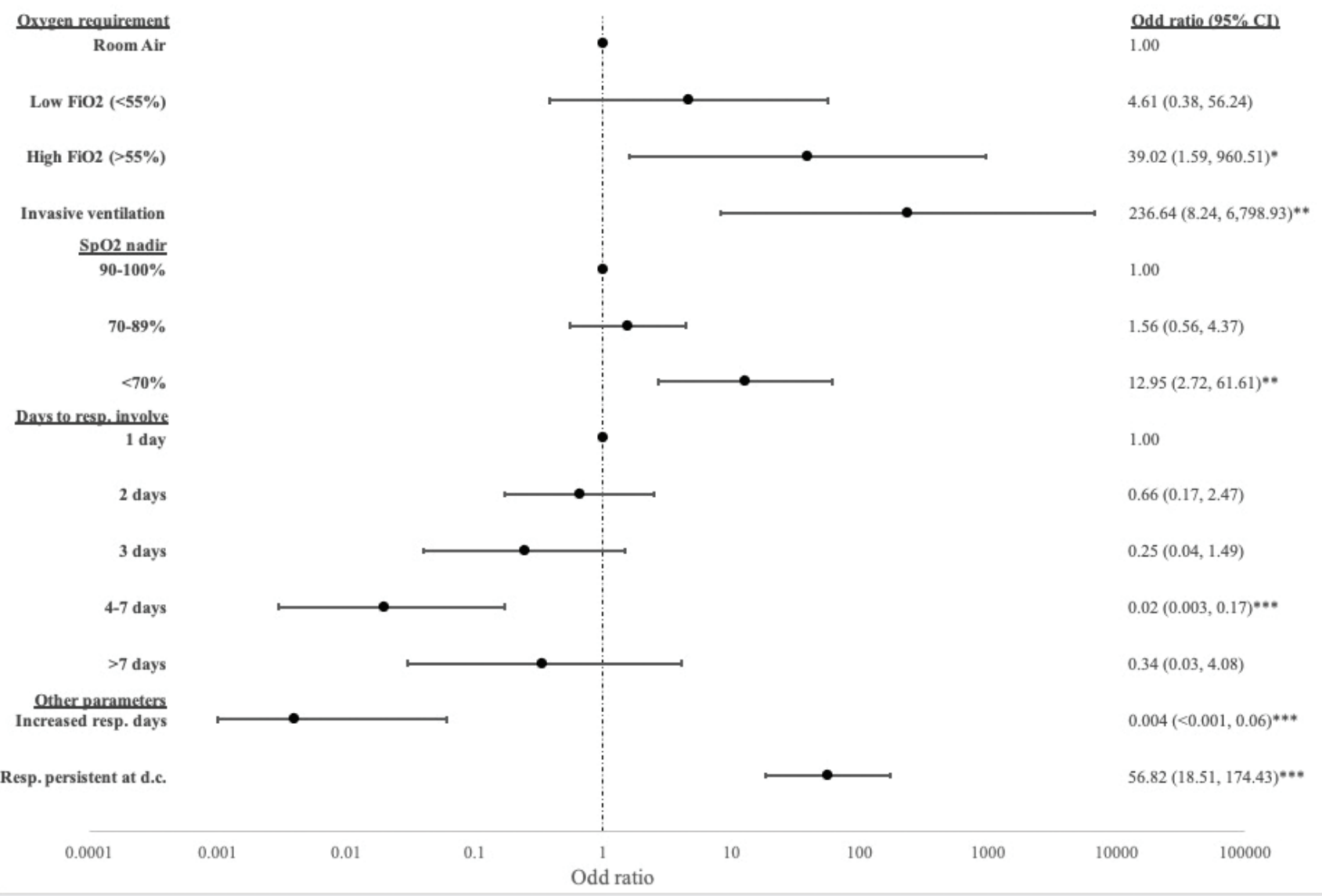

mortality and LOS in COVID-19 [1, 2, 5, 6, 15-17]. No studies have demonstrated this association after adjusting for all the involvement of other organ systems in COVID-19. We suggest that SARS-COV 2 is primarily a respiratory virus that affects the respiratory system; therefore, hospitalized COVID-19 patients who presented with severe respiratory symptoms were associated with worse prognosis.

We found that oxygen saturation nadir of $<70 \%$ was associated with increased odds for mortality, whereas oxygen saturation nadir of $70 \%-$ $89 \%$ during hospital stay was significantly associated with increased LOS. COVID-19 patients with oxygen saturation nadir of $<70 \%$ have more critical disease, and their increased mortality is in line with other studies showing higher mortality in critically ill COVID-19 patients [1, 2]. In contrast, those with oxygen saturation nadir of 70\%-89\% during hospitalization had a noncritical but severe disease process and required longer hospital stay until recovery and discharge. This is consistent with studies showing that severe COVID-19 increases the LOS [16, 17]. We suggest that the oxygen saturation nadir may be used as a prognostic tool in hospitalized COVID-19 patients.
We found that an increased proportion of days of respiratory system involvement was associated with decreased odds of mortality and an increased LOS. Other studies have also shown that COVID-19 survivors, as compared to COVID-19 patients who died in the hospital, have prolonged hospital stays likely due to respiratory sequala [18, 19]. Our findings are similar to this pattern. We suggest that for many patients, respiratory involvement is appropriately managed during their hospital stay with improving patient survival and extended patient LOS.

We found that respiratory involvement on days 2, 3, 4-7, and $>7$ was associated with increased LOS compared with respiratory involvement found on day of admission, and respiratory involvement on days 4-7 was associated with decreased odds of mortality. The onset of dyspnea on days 4-7 is a typical presentation for COVID-19 patients [4, 8, 9]. Patients presenting with respiratory involvement on the first day of hospitalization likely presented during a later course of their illness. We suggest that our patients who developed respiratory involvement in the hospital presented to the hospital earlier in their course of illness. Admission to the hospital at the early course of their illness resulted in 
TABLE 3

Linear regression analyses for length of stay

\begin{tabular}{|c|c|c|}
\hline Variables & Model 1 Univariate B (SE) & Model 2 Multivariate B (SE) \\
\hline \multicolumn{3}{|l|}{ Demographics } \\
\hline Age (years) & $-0.001(0.001)$ & - \\
\hline Sex (female) & $-0.08(0.03)^{* *}$ & $-0.04(0.02)$ \\
\hline \multicolumn{3}{|l|}{ Race/ethnicity } \\
\hline Caucasian & Reference & Reference \\
\hline African American & $-0.04(0.04)$ & $-0.01(0.03)$ \\
\hline Hispanic & $0.02(0.03)$ & $-0.002(0.02)$ \\
\hline East Asian & $-0.16(0.08)^{*}$ & $-0.08(0.05)$ \\
\hline Southeast Asian & $0.02(0.09)$ & $0.05(0.07)$ \\
\hline Other & $0.09(0.09)$ & $0.01(0.07)$ \\
\hline Insurance & & - \\
\hline Private & Reference & \\
\hline Uninsured/Emergency Medicaid & $0.02(0.04)$ & \\
\hline Regular Medicaid & $-0.06(0.04)$ & \\
\hline Medicare & $0.02(0.04)$ & \\
\hline \multicolumn{3}{|l|}{ Comorbidities } \\
\hline Tobacco use & & - \\
\hline Never & Reference & \\
\hline Former & $0.01(0.05)$ & \\
\hline Current & $0.07(0.08)$ & \\
\hline Unknown & $0.03(0.03)$ & \\
\hline Vaping & & - \\
\hline Never & Reference & \\
\hline Current & - & \\
\hline Unknown & $0.01(0.01)$ & \\
\hline Obese (yes) & $-0.03(0.03)$ & - \\
\hline $\mathrm{CCl}$ & $-0.004(0.01)$ & - \\
\hline \multicolumn{3}{|l|}{ Disease severity } \\
\hline qSOFA & $-0.01(0.02)$ & - \\
\hline ICU (yes) & $0.24(0.02)^{\star * \star}$ & $0.14(0.05)^{* *}$ \\
\hline Intubation admission (yes) & $-0.03(0.06)$ & - \\
\hline \multicolumn{3}{|l|}{ Oxygen requirement hospitalization } \\
\hline None & Reference & Reference \\
\hline Low $\mathrm{FiO}_{2}(\leq 55 \%)$ & $0.11(0.05)^{*}$ & $0.04(0.03)$ \\
\hline High $\mathrm{FiO}_{2}(>55 \%)$ & $0.25(0.04)^{* * *}$ & $-0.09(0.06)$ \\
\hline Invasive mechanical ventilation & $0.35(0.04)^{* * *}$ & $-0.08(0.06)$ \\
\hline \multicolumn{3}{|l|}{ Treatment management } \\
\hline Vasopressor (yes) & $0.21(0.03)^{\star * *}$ & $-0.004(0.03)$ \\
\hline Antibiotic (yes) & $0.21(0.06)^{\star *}$ & $0.13(0.05)^{\star \star}$ \\
\hline NSAID (yes) & $0.10(0.03)^{* *}$ & $0.05(0.02)^{*}$ \\
\hline ACEi/ARBS (yes) & $0.01(0.04)$ & - \\
\hline Antiviral (yes) & $0.22(0.09)^{*}$ & $0.12(0.06)$ \\
\hline Antimalarial (yes) & $0.10(0.04)^{\star *}$ & $0.02(0.03)$ \\
\hline Steroid (yes) & $0.33(0.03)^{* * *}$ & $0.10(0.02)^{* * *}$ \\
\hline Convalescent plasma (yes) & $0.54(0.05)^{\star * *}$ & $0.21(0.04)^{* * *}$ \\
\hline Interleukin inhibitor (yes) & $0.42(0.04)^{* * *}$ & $0.09(0.04)^{*}$ \\
\hline Anticoagulant (yes) & $0.30(0.03)^{\star * \star}$ & $0.07(0.03)^{*}$ \\
\hline \multicolumn{3}{|l|}{ Organ involvement } \\
\hline Respiratory plus other organ systems & $0.06(0.01)^{* * *}$ & $0.02(0.01)^{* *}$ \\
\hline \multicolumn{3}{|l|}{ Respiratory involvement } \\
\hline Oxygen saturation admission & - & \\
\hline $90-100$ & & Reference \\
\hline 70-89 & & $0.002(0.03)$ \\
\hline$<70$ & & $-0.03(0.06)$ \\
\hline Oxygen saturation nadir & - & \\
\hline $90-100$ & & Reference \\
\hline $70-89$ & & $0.07(0.03)^{*}$ \\
\hline$<70$ & & $0.05(0.04)$ \\
\hline Respiratory proportion days involved & - & $0.90(0.07)^{* * *}$ \\
\hline Days to respiratory involvement & - & \\
\hline 1 & & Reference \\
\hline 2 & & $0.20(0.03)^{\star * \star}$ \\
\hline 3 & & $0.33(0.05)^{\star * *}$ \\
\hline $4-7$ & & $0.49(0.05)^{\star * *}$ \\
\hline$>7$ & & $0.81(0.07)^{\star \star \star}$ \\
\hline Respiratory persistent involvement at discharge (yes) & - & $-0.15(0.02)^{\star \star \star}$ \\
\hline Constant & - & $-0.17(0.07)^{\star}$ \\
\hline
\end{tabular}

Note: $B=$ unstandardized beta, $S E=$ standard error, $C C I=$ Charlson Comorbidity Index, qSOFA = quick sepsis related organ failure assessment, $I C U=$ intensive care unit, $\mathrm{FiO}_{2}=$ fraction of inspired oxygen, NSAID = nonsteroidal anti-inflammatory drug, ACE $=$ angiotensin-converting-enzyme inhibitors, $A R B=$ angiotensin II receptor blockers, ${ }^{*} P<0.05,{ }^{* *} P<0.01,{ }^{* \star} P<0.001$, Model 2 adjusted $R$ Square $=0.52$. Respiratory plus other organ systems is the number of organ systems involved. 
longer LOS until completion of disease course and treatment and allowed for sufficient early treatment and closer monitoring of their disease course, and thus lower mortality on days 4-7. Patients who developed respiratory symptoms $>7$ days were not associated with mortality. It is important to note that the small sample size of the $>7$ days group limits the interpretation of our findings.

We found that persistent respiratory involvement at discharge was associated with increased odds of mortality and decreased LOS. This occurred because almost all patients who died in the hospital had respiratory involvement at discharge, whereas COVID-19 survivors were more likely to have improved and some resolved respiratory dysfunction. As other studies showed that COVID-19 patients who died in the hospital tended to have shorter LOS than COVID-19 survivors [19], this supports our explanation for the decreased LOS in our patients.

Among COVID-19 patients with respiratory involvement, we found that increased age was significantly associated with increased odds for mortality, which is consistent with prior studies $[2,5,20]$. Our data showed that sex, race/ethnicity, and insurance status were not associated with mortality or LOS. Findings on the association of sex, race/ethnicity, and insurance status with mortality and LOS are mixed. Some studies found that male gender, and African-American and Hispanic race/ ethnicity were associated with worse outcomes and increased mortality $[2,21]$, whereas other studies that adjusted for comorbidities and socioeconomic status did not find these negative associations [22-24]. Our adjusted analyses are consistent with the latter studies.

Surprisingly, we found that current tobacco use was associated with decreased odds of mortality. The results of the studies looking at the association between tobacco use and COVID-19 mortality are contradictory and inconclusive. Some studies reported that active smoking is associated with higher COVID-19 mortality [25, 26], others reported that current smoking is not associated with COVID-19 mortality [27], and some reported decreased COVID-19 mortality and severity in active smokers [5, 28]. The discrepancy of association in multiple other studies is due to limitations of studies on smoking and COVID-19 severities. Most studies did not separate current and former smokers, and the reported prevalence in these studies was lower than the country's smoking prevalence [26]. Although our data suggest that active smoking may be protective for COVID-19 mortality, it should be interpreted with caution as close to one-quarter of our patients had unknown tobacco use status. Definitive risk versus protection of tobacco use in COVID-19 should be further investigated.

We found that ICU level of care was not associated with mortality, but was significantly associated with increased LOS. Multiple studies with COVID-19 patients reported that ICU admission increases mortality $[4,17]$. In our study, the ICU level of care was provided to patients requiring close monitoring of their respiratory status in addition to patients with critical illness. This might have resulted in ICU level of care not having an impact on mortality in this patient group; however, we found an increased LOS in these patients. Our study is consistent with others that show ICU stay in COVID-19 is associated with increased LOS [29], likely because patients have a longer of stay in the ICU.

We found that $\mathrm{FiO}_{2}>55 \%$ and mechanical ventilation were each associated with increased odds for mortality. These findings are consistent with other studies $[2,5]$. We found no association between CCI and qSOFA adjusted for other variables and mortality. CCI was designed to estimate mortality based on chronic illnesses but not tailored to estimate risk in COVID-19 [11]. Multiple disease severity scoring systems were examined to assess COVID-19 prognosis, but none was validated or adopted for common use [30]. Our finding of no association between clinical scoring systems such as CCI and qSOFA and COVID-19 mortality is consistent with other studies [30, 31].

We found that vasopressor use was significantly associated with increased odds for mortality. The increased mortality with vasopressor use in COVID-19 is consistent with other studies [32]. We found that the use of antibiotics, NSAIDs, steroids, convalescent plasma, IL6 inhibitors, and anticoagulants was associated with increased LOS but not with mortality. Other studies showed no difference in hospital LOS with steroid, convalescent plasma, or IL6 inhibitor use [33-35]. We attribute the association with increased LOS in our study to the need of staying in the hospital to complete the treatment course, which is supported by other studies $[16,36]$. We did not find any association between antiviral use and mortality likely due to the small sample size and because remdesevir was not available at the early phase of the pandemic. Unlike other studies [37], we did not find any mortality benefit of steroid use as there were no standardized guidelines for steroid administration during the early phase of the pandemic. Inconsistent and varying administration of steroids might not have provided protection against COVID-19.

\section{Study limitations}

Our study had several limitations. First, this was a retrospective study conducted at a single center. We studied a large and diverse population in the New York metropolitan area. However, a multi-center study could provide a larger sample and be more representative of the general population in the United States. Further prospective studies should also be conducted to investigate the causal relationships of respiratory parameters. Second, objective laboratory values such as arterial blood gas findings were not available, as these laboratory tests were not routinely obtained during the pandemic. Future studies should investigate respiratory laboratory tests in COVID-19 patients and their association with clinical outcomes. Third, as the study was conducted in the early phases of the pandemic, there is no set standardized treatment procedure, therefore making it difficult to assess the effect of treatment.

\section{CONCLUSION}

We found that respiratory involvement adjusted for all other organ system involvement was significantly associated with increased odds of mortality and increased LOS. COVID-19 patients with respiratory involvement had increased mortality with $\mathrm{FiO}_{2}>55 \%$ and mechanical ventilation during hospitalization. Oxygen saturation nadir of $70 \%-$ $89 \%$ during hospital stay was significantly associated with increased LOS, whereas oxygen saturation nadir of $<70 \%$ was associated with increased odds for mortality. An increased proportion of days in hospital of respiratory system involvement was associated with decreased odds for mortality and increased LOS. Respiratory involvement on days 4-7 was associated with decreased odds for mortality, and respiratory involvement on day $>1$ was associated with increased LOS compared to respiratory involvement found on day of admission. Persistent respiratory involvement at discharge was associated with increased odds for mortality and decreased LOS. These data may provide insight into assessing clinical prognosis of tailoring treatment for COVID-19 hospitalized patients with respiratory involvement.

\section{DISCLOSURES}

\section{Contributors}

EL: study design, data acquisition, data interpretation, drafting manuscript, manuscript approval

SGP: study design, data acquisition, data interpretation, revising manuscript, manuscript approval

DGH: data acquisition, revising manuscript, manuscript approval YNP: data acquisition, revising manuscript, manuscript approval

JF: study design, data interpretation, data analysis, revising manuscript, manuscript approval

SR: study design, data interpretation, revising manuscript, manuscript approval

\section{Funding}

This study did not receive any specific grant from funding agencies in the public, commercial, or not-for-profit sectors.

\section{Competing interests}

All authors have completed the ICMJE uniform disclosure form at www. icmje.org/coi_disclosure.pdf and declare: no financial relationships with any organizations that might have an interest in the submitted work in the previous 3 years; no other relationships or activities that could appear to have influenced the submitted work. 


\section{Ethical approval}

The IRB of the local institution approved the study. A waiver for informed consent was received due to the retrospective nature of the study.

\section{REFERENCES}

1. Guan WJ, Ni ZY, Hu Y, Liang WH, Ou CQ, He JX, et al. Clinical characteristics of coronavirus disease 2019 in China. N Engl J Med 2020;382(18):1708-20. doi: 10.1056/NEJMoa2002032.

2. Richardson S, Hirsch JS, Narasimhan M, Crawford JM, McGinn T, Davidson KW, et al. Presenting characteristics, comorbidities, and outcomes among 5700 patients hospitalized with COVID-19 in the New York City area. JAMA 2020;323(20):2052-9. doi: 10.1001/ jama.2020.6775.

3. Gupta A, Madhavan MV, Sehgal K, Nair N, Mahajan S, Sehrawat TS, et al. Extrapulmonary manifestations of COVID-19. Nat Med 2020;26(7):1017-32. doi: 10.1038/s41591-020-0968-3.

4. Huang C, Wang Y, Li X, Ren L, Zhao J, Hu Y, et al. Clinical features of patients infected with 2019 novel coronavirus in Wuhan, China. Lancet 2020;395(10223):497-506. doi: 10.1016/S0140-6736(20)30183-5.

5. Petrilli CM, Jones SA, Yang J, Rajagopalan H, O'Donnell L, Chernyak Y, et al. Factors associated with hospital admission and critical illness among 5279 people with coronavirus disease 2019 in New York City: prospective cohort study. BMJ 2020;369:m1966. doi: 10.1136/bmj.m1966.

6. Becerra-Muñoz VM, Núñez-Gil IJ, Eid CM, García Aguado M, Romero $\mathrm{R}$, Huang J, et al. Clinical profile and predictors of in-hospital mortality among older patients hospitalised for COVID-19. Age Ageing 2021;50(2):326-34. doi: 10.1093/ageing/afaa258.

7. Rosenthal N, Cao Z, Gundrum J, Sianis J, Safo S. Risk factors associated with in-hospital mortality in a US National sample of patients with COVID-19. JAMA Netw Open 2020;3(12):e2029058. doi: 10.1001/ jamanetworkopen.2020.29058.

8. Wang D, Hu B, Hu C, Zhu F, Liu X, Zhang J, et al. Clinical characteristics of 138 hospitalized patients with 2019 novel coronavirus-infected pneumonia in Wuhan, China. JAMA 2020;323(11):1061-9. doi: 10.1001/ jama.2020.1585.

9. Cohen PA, Hall LE, John JN, Rapoport AB. The early natural history of SARS-CoV-2 infection: clinical observations from an urban, ambulatory COVID-19 clinic. Mayo Clin Proc 2020;95(6):1124-6. doi: 10.1016/j. mayocp.2020.04.010.

10. Wu C, Chen X, Cai Y, Xia J, Zhou X, Xu S, et al. Risk factors associated with acute respiratory distress syndrome and death in patients with coronavirus disease 2019 pneumonia in Wuhan, China. JAMA Intern Med 2020;180(7):934-43. doi: 10.1001/jamainternmed.2020.0994.

11. Quan H, Li B, Couris CM, Fushimi K, Graham P, Hider P, et al. Updating and validating the Charlson comorbidity index and score for risk adjustment in hospital discharge abstracts using data from 6 countries. Am J Epidemiol 2011;173(6):676-82. doi: 10.1093/aje/kwq433.

12. Seymour CW, Liu VX, Iwashyna TJ, Brunkhorst FM, Rea TD, Scherag A, et al. Assessment of clinical criteria for sepsis: for the third international consensus definitions for sepsis and septic shock (Sepsis-3). JAMA 2016;315(8):762-74. doi: 10.1001/jama.2016.0288.

13. Mehta RL, Kellum JA, Shah SV, Molitoris BA, Ronco C, Warnock DG, et al. Acute Kidney Injury Network: report of an initiative to improve outcomes in acute kidney injury. Crit Care 2007;11(2):R31. doi: 10.1186/ cc5713.

14. Teasdale G, Maas A, Lecky F, Manley G, Stocchetti N, Murray G. The Glasgow Coma Scale at 40 years: standing the test of time. Lancet Neurol 2014;13(8):844-54. doi: 10.1016/S1474-4422(14)70120-6.

15. Yang X, Yu Y, Xu J, Shu H, Xia J, Liu H, et al. Clinical course and outcomes of critically ill patients with SARS-CoV-2 pneumonia in Wuhan, China: a single-centered, retrospective, observational study. Lancet Respir Med 2020;8(5):475-81. doi: 10.1016/S2213-2600(20)30079-5.

16. Liu X, Zhou H, Zhou Y, Wu X, Zhao Y, Lu Y, et al. Risk factors associated with disease severity and length of hospital stay in COVID-19 patients. J Infect 2020;81(1):e95-7. doi: 10.1016/j.jinf.2020.04.008.

17. Suleyman G, Fadel RA, Malette KM, Hammond C, Abdulla H, Entz A, et al. Clinical characteristics and morbidity associated with coronavirus disease 2019 in a series of patients in metropolitan Detroit. JAMA Netw Open 2020;3(6):e2012270. doi: 10.1001/jamanetworkopen.2020.12270.

18. Huang Y, Tan C, Wu J, Chen M, Wang Z, Luo L, et al. Impact of coronavirus disease 2019 on pulmonary function in early convalescence phase. Respir Res 2020;21(1):163. doi: 10.1186/s12931-020-01429-6.
19. Rees EM, Nightingale ES, Jafari Y, Waterlow NR, Clifford SB, Pearson CA, et al. COVID-19 length of hospital stay: a systematic review and data synthesis. BMC Med 2020;18(1):270. doi: 10.1186/s12916020-01726-3.

20. Guo A, Lu J, Tan H, Kuang Z, Luo Y, Yang T, et al. Risk factors on admission associated with hospital length of stay in patients with COVID-19: a retrospective cohort study. Sci Rep 2021;11(1):7310. doi: 10.1038/ s41598-021-86853-4.

21. Williamson EJ, Walker AJ, Bhaskaran K, Bacon S, Bates C, Morton CE, et al. Factors associated with COVID-19-related death using OpenSAFELY. Nature 2020;584(7821):430-6. doi: 10.1038/s41586-020-2521-4.

22. Muñoz-Price LS, Nattinger AB, Rivera F, Hanson R, Gmehlin CG, Perez A, et al. Racial disparities in incidence and outcomes among patients with COVID-19. JAMA Netw Open 2020;3(9):e2021892. doi: 10.1001/ jamanetworkopen.2020.21892.

23. Price-Haywood EG, Burton J, Fort D, Seoane L. Hospitalization and mortality among black patients and white patients with Covid-19. N Engl J Med 2020;382(26):2534-43. doi: 10.1056/NEJMsa2011686.

24. Kabarriti R, Brodin NP, Maron MI, Guha C, Kalnicki S, Garg MK, et al. Association of race and ethnicity with comorbidities and survival among patients with COVID-19 at an urban medical center in New York. JAMA Netw Open 2020;3(9):e2019795. doi: 10.1001/jamanetworkopen. 2020.19795.

25. Patanavanich R, Glantz SA. Smoking is associated with COVID-19 progression: a meta-analysis. Nicotine Tob Res 2020;22(9):1653-6. doi: $10.1093 / \mathrm{ntr} / \mathrm{ntaa} 082$.

26. Zhao Q, Meng M, Kumar R, Wu Y, Huang J, Lian N, et al. The impact of COPD and smoking history on the severity of COVID-19: a systemic review and meta-analysis. J Med Virol 2020;92(10):1915-21. doi: 10.1002/ jmv.25889.

27. Lippi G, Henry BM. Active smoking is not associated with severity of coronavirus disease 2019 (COVID-19). Eur J Intern Med 2020;75:107-8. doi: $10.1016 /$ j.ejim.2020.03.014.

28. The OpenSAFELY Collaborative, Williamson E, Walker AJ, Bhaskaran $\mathrm{K}$, Bacon S, Bates C, et al. OpenSAFELY: factors associated with COVID-19-related hospital death in the linked electronic health records of 17 million adult NHS patients. Nature 2020;584:430-6. doi: 10.1101/ 2020.05.06.20092999.

29. Argenziano MG, Bruce SL, Slater CL, Tiao JR, Baldwin MR, Barr RG, et al. Characterization and clinical course of 1000 patients with coronavirus disease 2019 in New York: retrospective case series. BMJ 2020;369:m1996. doi: 10.1136/bmj.m1996.

30. Wynants L, Van Calster B, Collins GS, Riley RD, Heinze G, Schuit E, et al. Prediction models for diagnosis and prognosis of covid-19 infection: systematic review and critical appraisal. BMJ 2020;369:m1328.

31. Bradley P, Frost F, Tharmaratnam K, Wootton DG; NW Collaborative Organisation for Respiratory Research. Utility of established prognostic scores in COVID-19 hospital admissions: multicentre prospective evaluation of CURB-65, NEWS2 and qSOFA. BMJ Open Respir Res 2020;7(1):e000729. doi: 10.1136/bmjresp-2020-000729.

32. Auld SC, Caridi-Scheible M, Blum JM, Robichaux C, Kraft C, Jacob JT, et al. ICU and ventilator mortality among critically ill adults with coronavirus disease 2019. Crit Care Med 2020;48(9):e799-e804. doi: 10.1097/ CCM.0000000000004457.

33. Devasenapathy N, Ye Z, Loeb M, Fang F, Najafabadi BT, Xiao Y, et al. Efficacy and safety of convalescent plasma for severe COVID-19 based on evidence in other severe respiratory viral infections: a systematic review and meta-analysis. CMAJ 2020;192(27):E745-55. doi: 10.1503/cmaj. 200642.

34. Pinzon RT, Wijaya VO, Buana RB. Interleukin-6 (IL-6) inhibitors as therapeutic agents for coronavirus disease 2019 (COVID-19): a systematic review and meta-analysis. J Infect Public Health 2021;14(8):1001-9. doi: 10.1016/j.jiph.2021.06.004.

35. van Paassen J, Vos JS, Hoekstra EM, Neumann KMI, Boot PC, Arbous SM. Corticosteroid use in COVID-19 patients: a systematic review and meta-analysis on clinical outcomes. Crit Care 2020;24(1):696. doi: 10.1186/s13054-020-03400-9.

36. Anderson MR, Bach PB, Baldwin MR. Hospital length of stay for patients with severe COVID-19: implications for remdesivir's value. Pharmacoecon Open 2021;5(1):129-31. doi: 10.1007/s41669-020-00243-6.

37. RECOVERY Collaborative Group, Horby P, Lim WS, Emberson JR, Mafham M, Bell JL, et al. Dexamethasone in hospitalized patients with Covid-19. N Engl J Med 2021;384(8):693-704. doi: 10.1056/ NEJMoa2021436. 